\title{
Value Typology In Cost-Benefit Analysis
}

Seth D. Baum, http://sethbaum.com

Department of Geography \& Rock Ethics Institute, Pennsylvania State University

Published in: Environmental Values, 2012, 21(4): 499-524. This version: 11 September 2012.

\begin{abstract}
Cost-benefit analysis (CBA) evaluates actions in terms of negative consequences (costs) and positive consequences (benefits). Though much has been said on CBA, little attention has been paid to the types of values held by costs and benefits. This paper introduces a simple typology of values in CBA and applies it to three forms of CBA: the common, money-based CBA, CBA based in social welfare, and CBA based in intrinsic value. The latter extends CBA beyond its usual anthropocentric domain. Adequate handling of value typology in CBA avoids analytical mistakes and connects $\mathrm{CBA}$ to its consequentialist roots.
\end{abstract}

Key Words: Cost-benefit analysis, value typology, consequentialism, social welfare, welfare economics

\section{Introduction}

Suppose we are conducting a cost-benefit analysis (CBA) about whether to preserve a tree or allow it to be cut by a lumber company. Benefits of preservation could include such services as the tree's shade, its beauty, and perhaps some carbon dioxide sequestration. Following conventional CBA practice (e.g. Pearce et al. 2006), we might convert these various services into monetary units based on how much people would be willing to pay for them. If people would be willing to pay more for the preservation than for the cutting, then the benefits of preservation would exceed the costs, preservation would pass the CBA, and we would recommend preservation.

In this simple example each cost or benefit appears in three forms. First, there is the service itself, such as the shade or the beauty. Second, there is the monetary representation of the service, which is the form used in the CBA. In the economics jargon, the unit used in the analysis is the numéraire. Finally, there is the human desire - commonly described as a preference - for the service, which motivates the willingness to pay for it. Each form has a different function: the service causes the preference satisfaction, and the amount of satisfaction is represented in the monetary units. But each form derives from the same cost or benefit. We would not count the tree's shade separately from the satisfaction we get from it or the money we would pay for it. To do so would be to count the same benefit multiple times.

In this paper I wish to discuss the functional relationships of the various forms of costs and benefits found in CBAs. In the language developed here, different functionalities correspond with different types of value. That costs and benefits hold (or at least are considered to hold) value should be clear: costs hold negative value; benefits hold positive value. To deny that costs and benefits hold value is to deny that CBA has any meaning as an evaluative procedure. Such a 
denial could be made but will not be considered here. Instead I assume that costs and benefits hold value. I do not, however, assume that CBA must follow the conventional valuation procedure illustrated above and developed in an expansive literature (e.g. Boadway and Bruce 1984; Layard and Glaister 1994; Mishan 1975; Sugden and Williams 1978; Adler and Posner 2000; 2006; Fuggitt and Wilcox 1999) and also extensively criticized (e.g. Ackerman and Heinzerling 2004; Anderson 1993; Sagoff 2008; Soma 2006; Spash 2008). Instead, I consider a much broader interpretation of the term ' $\mathrm{CBA}$ ', including some innovations in how CBA can be interpreted and implemented.

The value typology I develop here comes not from the economics and CBA literature but from philosophy. At the core of the philosophy typology is the distinction between intrinsic value (that which is valuable for its own sake: Rønnow-Rasmussen and Zimmerman 2005) and extrinsic value (all other value: Bradley 1998). This typology is heavily used in the environmental ethics literature, in particular to discuss whether nonhuman phenomena such as ecosystems hold intrinsic value (c.f. Callicott 2002; McShane 2008; Norton 2008). Here I attempt to bring insights from this conversation to bear on CBA. Meanwhile, the CBA literature often discusses intrinsic value (c.f. Adler and Posner 2006: 156; Pearce et al. 2006: 87-88), but these discussions are generally crude and incomplete. Extrinsic value gets even less attention, with most treatments of CBA simply neglecting the different types of extrinsic value found in CBA. The economics literature does have a well-developed value typology of its own, featuring value types such as use value and existence value (Crowards 1997); this typology is also useful for CBA but in ways different from the typology from the philosophy literature.

The philosophy value typology offers a richer understanding of how to interpret and implement CBA and suggests new innovations in CBA design. Neglecting this value typology can lead to weak CBA formulations and in turn worse recommendations. Regrettably, such mistakes are commonplace in CBA. For the conventional CBA illustrated above, which I will refer to as money-based $C B A$, the value typology informs ongoing debates about the CBA's ethical foundations and role in decision making (Adler and Posner 2000; 2006), with particular relevance to CBAs of environmental decisions (Ackerman and Heinzerling 2004; Sagoff 2008; Soma 2006; Spash 2008). The value typology also clarifies the workings of a related but separate line of CBA theory developed in the economics literature, grounded in social welfare functions (Drèze and Stern 1987; 1990). Finally, my discussion of value typology in this social welfarebased $C B A$ readily suggests a third form of CBA, which I call intrinsic value-based $C B A$. Intrinsic value-based CBA permits CBA using a broad range of consequentialist ethics - perhaps the full breadth. Though it seldom appears in the literature (but see Sen 2000), a strong argument can be made for including it within the realm of 'CBA'. Thus, as Lenman (2000: 431) notes, it is a mistake to think of CBA as a single, monolithic procedure. Instead, it is a class of procedures, featuring a diverse and often contradictory literature.

The question of just what the term ' $\mathrm{CBA}$ ' refers to merits further comment. There is confusion on this in the literature, such as in the distinction between money-based and social welfare-based CBA. Also here I will use this term in somewhat new ways, mainly for intrinsic value-based CBA. Of these three forms of CBA, the money-based CBA is by far the most widely used, to such an extent that it has achieved a certain epistemic dominance: when we hear the term 'CBA', this is often what we think of. I have personally witnessed many people surprised at the idea that 
costs and benefits can be measured in anything other than monetary units, and that even monetized costs and benefits leave much flexibility in how the aggregate analysis proceeds. Thus Aldred (2002: 28-29) is correct in observing that while CBA can refer broadly to "weighing the "benefits" against the "costs" of some proposal... in practice monetary valuation is effectively universal in CBA'.

To some extent, how we use the term ' $\mathrm{CBA}$ ' is only a matter of semantics. As long as we get the analysis itself right, what terms we use to describe the analysis can be unimportant. We can disagree on the meaning of ' $\mathrm{CBA}$ ' while agreeing on how to conduct the analysis, whether that analysis is ' $\mathrm{CBA}$ ' or not. But this is only true to an extent. Terminology matters, because it influences how we think and what we do. For 'CBA', the assumption of using the money-based form brings a tendency to monetize all consequences of potential actions, thereby biasing decisions in certain directions. One direction is towards the preferences of the wealthy (Adler and Posner 2006: 130-131); another is towards increases in possibly-undesirable economic growth (Spash 2007: 710). Furthermore, monetizing costs and benefits risks offending those who reject the use of a monetary numéraire (Hansson 2007: 177; Anderson 1993, Chapter 9).

Terminology, and in particular its interpretation, are important not just for theory but also for practice. We would be wise to, like Callicott (2002: 4), 'appreciate the power of names, and of discourse, more generally, in the formation of environmental policy' - and in the formation of other actions as well. This is, in the social theorist's jargon, the performativity of discourse. I thus urge the reader to maintain an open mind with regards to what the term 'CBA' can refer to, and in particular to consider that it can refer to analysis beyond the conventional money-based form.

It is not my goal in this paper to argue for or against CBA or any of its three forms. My own views do coincide with one form of CBA, namely the intrinsic value-based CBA, specifically where intrinsic value is defined to include the welfare of both humans and non-humans, and where welfare is defined in a specific way, namely in terms of subjective experience, as outlined for example in Kahneman and Sugden (2005) and $\mathrm{Ng}$ (2003). In a recent paper O'Neill (2008) offers a critique of this view arguing for there to also be intrinsic value in the narrative of a life story. I am quite sympathetic to O'Neill's argument but ultimately disagree with it. However, while argument for and against the various forms is extremely important, it requires dedicated space and would distract from my core goal regarding value typology. This goal is to develop the philosophy value typology as it is relevant to the CBA literature and illustrate its importance. Proper attention to value typology in CBA enhances conceptual precision and can help avoid analytical mistakes, regardless of what form of CBA is in use. Thus, attention to value typology in CBA is of both intellectual and practical interest.

\section{Value Typology}

Value typology concerns not 'What holds value?' but 'What type of value does it hold?'. Value can come in a wide variety of types. Here I present a simple value typology suitable for discussions of CBA. As noted above, this value typology is derived from the philosophy literature. I also briefly introduce economics value typology and discuss its relation to the philosophy value typology. More detailed discussions of philosophy value typology can be found 
in Rønnow-Rasmussen and Zimmerman (2005) and Bradley (1998); for the economics value typology, see Crowards (1997).

Philosophical discussion of value typology has covered a broad range of ethical frameworks. Here, discussion is restricted to consequentialist frameworks. This restriction follows from the present focus on CBA, which is generally justified by consequentialism of one form or another (Sen 2000). The idea that CBA is consequentialist holds for each of the money-based, social welfare-based, and intrinsic value-based CBA forms. In each of these forms, costs are bad consequences and benefits are good consequences. Clearly specifying which consequentialist frameworks the forms employ and what value types the costs and benefits hold within these frameworks is a main focus of this paper. First some additional detail on value typology is warranted.

Following the philosophy literature, I divide value types into two categories: intrinsic value, which is that which is valuable for its own sake, and extrinsic value, which includes all other value types. I consider two types of extrinsic value: instrumental value, which is valuable because it causes other value, and signatory value, which is valuable because it signifies the occurrence of other value.

\section{Intrinsic Value}

Intrinsic value is that which is valuable for its own sake. What phenomena hold intrinsic value corresponds with what ethical framework is in effect. For example, in contemporary discussions of utilitarianism, utility holds intrinsic value. To avoid confusion, it is worth noting that in earlier writings about utilitarianism, the term 'utility' may have referred to phenomena that held instrumental value, which is a form of extrinsic value (Cooter and Rappoport 1984; Broome 1991). Also, 'utility' in common vernacular means 'usefulness', which roughly equates with instrumental value. Meanwhile, in consequentialist forms of ecocentric ethics (Holbrook 1997), ecosystem fitness holds intrinsic value. In a pluralistic ethical framework, multiple phenomena hold intrinsic value. Such pluralistic ethics could correspond with the multicriterion frameworks often advocated in the environmental ethics literature (e.g. Beinat and Nijkamp 1998; Munda 1995; Janssen 1992; Soma 2006).

For our discussion of CBA, it is helpful to distinguish between what I will call component and total intrinsic value. Component intrinsic value is the intrinsic value of a component of a system. Total intrinsic value is the intrinsic value of an entire system. For example, in contemporary utilitarianism an individual's utility holds component intrinsic value and the total sum of all utility holds total intrinsic value. In consequentialist ecocentrism, a pond holds component intrinsic value, and all of the ecosystems in the world (and perhaps beyond) holds total intrinsic value. As discussed below, the social welfare-based CBA defines total intrinsic value via a social welfare function; here individual welfare holds component intrinsic value. The intrinsic valuebased CBA generalizes the social welfare function to accommodate any consequentialist definition of total intrinsic value.

Total intrinsic value can be but need not be the unweighted, linear sum of all component intrinsic value. An unweighted sum is used, for example, in classical utilitarianism, where all units of 
utility are counted equally towards the total sum. Weighted sums, or other nonlinear functions, are used often. For example, the ethics of prioritarianism counts the welfare of the worse-off more than the welfare of the better-off (McCarthy 2008). The possibility that intrinsic value could sum in a weighted, non-linear fashion was introduced by Moore (1903) as the principle of organic unities. Here, total intrinsic value does not equal the sum of the component intrinsic values but instead some other functional relationship exists.

The principle of organic unities should not be confused with what I will call favoritism, in which different manifestations of the same phenomenon hold different amounts of intrinsic value. For example, I might favor my utility over your utility, meaning that I might place more intrinsic value my own utility than on your utility (Baum and Easterling 2010). Favoritism thus concerns the relationship between the magnitude of a phenomenon and its component intrinsic value, whereas the principle of organic unities concerns the relationship between component and total intrinsic value. Careful accounting is necessary to keep track of these various quantities.

\section{Extrinsic Value: Instrumental and Signatory Value}

Extrinsic value is value that is not intrinsic value. Extrinsic value is defined in relation to some other value. This other value can either be an intrinsic value or another extrinsic value. However, all extrinsic value must always relate to an intrinsic value, even if this relation is via one or more other extrinsic values. This requirement exists because extrinsic value by definition cannot introduce value into a system - only intrinsic value can do so.

For discussions of CBA, two types of extrinsic value are important. The first of these is instrumental value. Instrumental value is that which is valuable because it causes other value. Instrumental value is by far the most commonly discussed type of extrinsic value (Bradley 1998). Indeed, many discussions equate extrinsic value with instrumental value, or otherwise neglect the possibility of other types of extrinsic value. For example, Callicott (2002: 12) considers the issue of "whether we think of nature as having intrinsic value or only instrumental value' but does not consider whether nature (or anything else) might hold other types of extrinsic value. In critiquing this typology, McShane (2008: 17) is thus correct in observing that it 'doesn't seem to leave any room for a thing to be extrinsically valuable in a way that is not instrumental'. Instrumental value is undoubtedly an important type of extrinsic value, both in CBA and elsewhere, but it is not the only type, or the only important type.

The other important type of extrinsic value for CBA is signatory value. Signatory value is that which is valuable because it signifies (but does not cause) the occurrence of other value. The distinction between signatory value and instrumental value, as well as the relationship between both of these and intrinsic value, can be observed in the simple tree example introduced above. In this example, human preference satisfaction holds intrinsic value. The tree's services - shade, beauty, etc. - hold instrumental value because they cause preference satisfaction. The monetary representation of people's willingness to pay for the services is a signatory value because it signifies the strength of the preference for the services. Also here water could hold instrumental value if it could cause the tree to flourish which would in turn cause the tree to provide services. Likewise, a report describing the fitness of the tree could hold signatory value if it signifies the ability of the tree to provide services. These are the sorts of functional relationships between 
different types of values that appear throughout CBA but generally go overlooked as all costs and benefits are converted to a common numéraire.

A bit more should be said about signatory value. For it to be a useful sign, the magnitude of a signatory value must correlate with the magnitude of whatever value it signifies. However, this correlation need not be a linear correlation such that each unit of the signatory value maps to the same magnitude of the signified value. Where the correlation is linear, the signatory value will be called a perfect sign. Likewise, where the correlation is non-linear, the signatory value will be called an imperfect sign. For example, a monetary representation of willingness to pay is a perfect sign if and only if it scores the willingness to pay such that one score point corresponds with one unit of preference satisfaction. If instead the report does not relate to preference satisfaction in this way, perhaps because it fails to account for some important part of preference satisfaction, then it will be an imperfect sign. The concept of sign perfection is crucial to assessing the appropriateness of particular numéraires used in CBA.

Ultimately, the goal of any given action is to maximize total intrinsic value - or at least this is the ultimate goal in the consequentialist frameworks considered here. (For a more detailed discussion of intrinsic value and consequentialism that is largely compatible with the discussion in this paper, see Anderson 1993: 30-38). Information about extrinsic value can help us identify how to maximize total intrinsic value. Care must be taken in order to properly convert information about extrinsic value into information about total intrinsic value, just as it is also the case that care must be taken to properly convert information about component intrinsic value into information about total intrinsic value. Below I discuss how the three forms of CBA make these value conversions and how they handle value typology in general. First I offer some brief remarks on value typology in economics and its relation to the philosophy value typology presented here.

\section{Economic Value Typology}

The key conceptual difference between the value typologies of philosophy and economics is in the vantage point from which values are identified and defined. The philosophy typology focuses on the various ways in which phenomena can reasonably be stated to hold value. In contrast, the economics typology generally focuses on the various ways in which evaluating agents (who, we should note, are almost invariably assumed to be human beings) may value phenomena. In other words, the philosophy typology assigns value in a universalist, agent-independent 'God's eye view', whereas the economics typology assigns value in an agent-relative 'agent's eye view'. These two typologies thus serve different purposes and are fully compatible with each other.

Economists have identified a broad range of agent-relative value types (Pearce 1993; Crowards 1997; Soma 2006). The economic value typology is particularly robust in valuations of environmental phenomena, driven by the diverse relationships that can exist between these phenomena and evaluative agents. A primary distinction in economic value typology is between use value, i.e. the value an agent gets from using some phenomenon, with non-use value, i.e. the value an agent gets from the phenomenon existing without being used by the agent. For example, an agent may place use value on a tree because she can use the tree for its shade, or its wood, or its fruit. Alternatively, an agent may place non-use value on the tree because she wants the tree 
to remain available for her children to use (bequest value), or because she desires the tree's existence for its own sake (existence value).

As with the philosophy value typology, the economics value typology includes the term 'intrinsic value'. However, the economics typology uses the term in two different ways, both of which are subtly different from the use in the philosophy typology. First, the economics typology sometimes uses 'intrinsic value' to refer to phenomena which humans place intrinsic value on (Soma 2006: 35). The philosophy typology would consider this value to be instrumental value: the phenomena are valuable because they cause the satisfaction of the preferences of the humans who place intrinsic value on the phenomena. (In Section 3 below we will see that it is not necessarily preference satisfaction that holds intrinsic value, but this complication is not crucial to the present point.) Here the philosophy typology, taking its God's eye view, would say that only human preference satisfaction holds intrinsic value. Second, the economics typology sometimes uses 'intrinsic value' to refer to values held by nonhuman phenomena - especially environmental phenomena - independently of any human preferences (Crowards 1997: 155; Pearce et al. 2006: 87-88). The philosophy typology would also use 'intrinsic value' for such values: these nonhuman phenomena are valued for their own sake, as opposed to for their connection to human preference satisfaction. However, the philosophy typology is broader in that it would also allow that human preference satisfaction could hold intrinsic value. Indeed, in the ethics of virtually all economic valuations, human preference satisfaction (or something similar) holds what the philosophy typology would call intrinsic value. Furthermore, this preference-independent intrinsic value is typically treated as beyond the scope of CBA (Adler and Posner 2006: 156; Pearce et al. 2006: 87-88). This means that within a CBA, there is no economic intrinsic value, but there is philosophical intrinsic value (i.e. preference satisfaction). This is a rather confusing arrangement. To avoid confusion, unless otherwise specified, throughout this paper 'intrinsic value' will be used in the sense found in the philosophy typology.

How the economic value typology relates to the above philosophy value typology can be interpreted in two different ways. Note that here we're excluding any values that fall outside the realm of CBA, such as in the second use of 'intrinsic value' in the economics typology. The first interpretation argues that both use and non-use value are instrumentally valuable because they cause intrinsic value: satisfaction of the agent's preferences. Here the tree is valuable to the extent that it satisfies the evaluative agent's preferences based on how strongly she prefers to use the tree to further her own purposes, to pass it on to her descendents, or to keep it in existence unused. Thus any value the tree might hold must always relate to the evaluator's preferences. The second interpretation places some intrinsic value on the evaluator's preferences but also on other phenomena. These other phenomena are whatever the evaluator places intrinsic value on, i.e. whatever she deems to be valuable for its own sake. In our tree example, the preferences of the evaluator's children would hold intrinsic value if the evaluator places intrinsic value on the satisfaction of her children's preferences. Then the tree would hold instrumental value if the evaluator seeks to prolong the tree's existence specifically to satisfy her children's preferences. Meanwhile, the existence of the tree may also hold intrinsic value if the evaluator places intrinsic value on the tree. This would be the case if the evaluator places existence value on the tree, i.e. desires the tree's existence for its own sake. 
While these two interpretations vary in terms of how they connect the economic value typology to the philosophy value typology, they share one important feature: in both interpretations, evaluators decide what holds intrinsic value. If we remove the evaluators then all value disappears as well. So for example, there would be no value in a planet full of lush, vibrant ecosystems but completely lacking in any individuals capable of evaluating the ecosystems. Or, if a tree falls in the woods and nobody cares, then that fall is morally irrelevant. This conclusion is difficult to accept. The question of whether to accept it gets to the heart of the question of environmental existence value and other meta-ethical questions of the nature of intrinsic value. I will not pursue these questions further here (but see Lenman 2000, Aldred 1994, Hayward 1997 , and Callicott 2002, among others), although they resurface below in discussion intrinsic valuebased CBA.

\section{Value Typology in Money-Based CBA}

As noted above, money-based CBA is the by far the most widely used. Indeed, when left unqualified, CBA is generally assumed to be of a money-based form. Here all costs and benefits are measured in a monetary numéraire, and all dollars are counted equally (except for future dollars, which are typically discounted). Measurements of costs and benefits in money-based CBA are generally obtained via one of two procedures. First, measurements can be made by observing market prices, i.e. how much money can be obtained by exchanging various objects in actual markets. Second, measurements can be made by inquiring on willingness to pay, i.e. how much individuals would be willing to pay for various objects in hypothetical markets. In general, willingness to pay values will be higher than market values because individuals would be willing to pay more than market price. The difference between how much an individual would be willing to pay and the market price that she does pay is known as consumer surplus.

One important implication of the difference between market price and willingness to pay is that many major ecosystem services such as land and air have low or even zero market prices despite their importance to us. As Sagoff (2008) discusses, the very low market prices found for ecosystem services are because these services are in abundance. Certainly this is true, at least on Earth. Meanwhile, in the International Space Station, quite a lot of money is paid for air. Similarly, researchers have proposed going to great lengths to 'terraform' other planets so that humans can survive on other planets in outdoors environments (McKay et al. 1991; Mole 1995). Sagoff (2008) also denies the meaningfulness of willingness to pay as any type of value. This is a separate issue which I revisit below. Here I wish only to emphasize that while market prices for certain ecosystem services are very low on Earth, our willingness to pay for the totality of these services is very high (perhaps even infinite) regardless of how much we happen to have. In short, we have a very large consumer surplus from ecosystem services.

Most contemporary theoretical treatments of money-based CBA favor willingness to pay over market prices (e.g. Adler and Posner 2006; Pearce et al. 2006). However, many actual moneybased CBAs still use market prices. Furthermore, measurement via market price and measurement via willingness to pay bring very different CBAs, as is made clear from identifying the types of values held by these various CBAs. Thus, I will discuss value typology in moneybased CBAs using both market prices and willingness to pay. 
Consider first the market price CBA. This CBA counts costs and benefits in terms of how much money gets produced. So for example, the value of the above-discussed tree would be whatever money was produced from selling its shade, fruit, or wood, or from donations made to protect its existence (regardless of how much people would be willing to pay). Non-market values are omitted. If actual dollars do not flow for these purposes or for other purposes the tree might serve, then the tree is deemed to hold no value. Thus the correct action to take with respect to the tree is whichever action brings in the most actual dollars. If more money can be produced by dismembering the tree and selling its parts than by protecting its existence, then dismemberment is the correct action. Likewise, in evaluating an action that would destroy the tree in exchange for some other benefit, the cost of losing the tree would be the amount of money lost from no longer being able cash in on the tree's maximum market value. More generally, the market price CBA aims to identify those actions which bring in the most dollars, whether or not these actions involve trees.

In seeking to maximize actual dollars, the market price CBA appears to be placing intrinsic value on money. The items being exchanged in markets, whether trees or anything else, then hold instrumental value because they bring in money. Further, if we assume that net monetary benefits should be maximized no matter what, then we may be supporting an ethical framework that defines total intrinsic value as the sum of all money. To support such a framework would be to reject the principle that 'there is more to life than money'. For example, some people may be so obsessed with money that their own welfare and the welfare of others suffer. If intrinsic value is placed exclusively on money, then humans become extrinsic values (if they even hold any value at all). Humans could hold instrumental value because humans can create money. Humans could also hold signatory value if it is the case that societies with more humans tend to create more money. Ultimately, the correct actions would be those that produce more money. This conclusion has radical implications. One can imagine, for example, starving humans so as to reserve more resources for the production of money. Thus despite the obsessions of some, it is difficult to view ethical frameworks defining total intrinsic value exclusively in monetary terms as anything other than a philosophical mistake. Likewise, the market price CBA should be rejected.

Fortunately, most of us do not define total intrinsic value in terms of money only. Furthermore, most of us would not place any intrinsic value on money. Perhaps an exception can be found in coin collectors, if they value the coins simply for their existence. (Coin collectors may also place instrumental value on the coins in that the coins satisfy their preferences.) But this is a rare exception. In general, few people would place intrinsic value on money and thus few people would advocate the market price CBA. This includes most CBA theorists (though fewer practitioners), who by now generally justify money-based CBA on different ethical grounds. Early CBAs did tend to focus on market prices, although these CBAs did not go so far as to recommend that humans be harmed for the production of more money - instead, it 'was intended from the beginning as a strategy for limiting the play of politics in public investment decisions' (Porter 1995: 189). Modern theorists also often argue that CBA need not be the only relevant piece of information in the decision making process, a point I elaborate on below.

For several decades now, money-based CBA has most commonly been justified using willingness to pay instead of actual market prices, generally via the ethics of potential Pareto 
optimality (Adler and Posner 2006, Chapter 1). Pareto optimality (whether potential or actual) is a form of utilitarianism based on an ordinal view of utility, in contrast to classical utilitarianism, which is based on a cardinal view. The question of ordinal vs. cardinal utility has been heavily debated over many decades (Drakopoulos 1989; Elster and Roemer 1991), a debate which remains relevant to the ethical foundations of CBA. Given the notion of Pareto optimality, it follows that a potential Pareto improvement occurs if the winners of some program could potentially compensate the losers such that everyone is at least as well off and some individuals are better off than without the program, even if the compensation does not actually occur. The potential compensation concept is often named after Kaldor (1939) and Hicks (1939). An actual Pareto improvement occurs if the compensation is made. In the money-based CBA, potential compensation is monetary. Thus if one individual receives a benefit and another receives a cost such that the benefit-receiver could provide monetary compensation to the cost-receiver such that an actual Pareto improvement occurs, then this pairing of cost and benefit is considered an improvement regardless of who the receiving individuals are (for example, if the cost-receiver is quite poor) and regardless of whether compensation is paid. A state is (potential/actual) Pareto optimal when no more (potential/actual) Pareto improvements can be made.

The potential Pareto optimality and willingness to pay are connected in the following sense. The potential compensation in potential Pareto improvements can only occur when the benefitreceiver(s) are willing to pay more for the benefit(s) than would be necessary to compensate the cost-receiver(s). For example, suppose an action to build a new building would destroy a tree. A willingness to pay CBA would ask whether individuals were willing to pay more to keep the tree or to build the building. The building would be recommended if the building could be built such that after the actual monetary market cost of building the building, those who wanted the building would be willing to pay enough money to those who wanted the tree that then everyone is at least as well off, even if payment is not actually made. In other words, the building would be recommended if it brought a potential Pareto improvement. Thus the more individuals are willing to pay for something, the larger of a potential Pareto improvement results. Here both willingness to pay and potential Pareto improvements correspond with preference strength: the more we prefer something, the more we are willing to pay for it.

In the now-standard willingness to pay CBA, there is some ambiguity in what holds intrinsic value and what types of values are held by the phenomena involved. In the tree example in the Introduction, the amount of money someone was willing to pay was a signatory value, signifying the strength of that person's preference. However, for CBA to proceed under this interpretation, preference strength would need to be measurable with a cardinal scale and comparable across individuals. Otherwise we would not be able to add up willingness to pay values in order to find the total costs and benefits of the various options under consideration. But defenses of willingness to pay CBA generally assume ordinal preference. Furthermore, if willingness to pay did signify a cardinal preference strength, then it would not be a perfect sign unless dollars were weighted by wealth (and perhaps by other factors as well). The sign imperfection would mistakenly favor the preferences of the wealthy. This can be seen clearly by imagining a theft victim. After the theft, she may not be willing to pay as much money for, say, a tree's services, simply because she has less money available to pay. But the theft would in general not affect the strength of her preference for the tree's services, meaning that a post-theft reduction in willingness to pay does not signify a reduction in preference strength. Thus, whether due to 
cardinality or to sign imperfection, the conventional unweighted willingness to pay CBA cannot be justified by having willingness to pay signify preference strength.

Another simple approach would be if the potential Pareto improvement holds intrinsic value. Consider the potential Pareto improvement. It could hold component intrinsic value. Since money-based CBA seeks to maximize potential Pareto improvements, it follows that total intrinsic value is defined as the (generally unweighted) sum of potential Pareto improvements. Here money itself holds signatory value, since it signifies the occurrence of potential Pareto improvements. The magnitude of the potential Pareto improvement caused by some action is signified by the amount of money that individuals are willing to pay for that action to occur. The money that individuals are willing to pay is of a hypothetical nature, since the individuals need not actually pay. For example, if I am willing to pay $\$ 100$ to save a tree, then saving the tree causes a $\$ 100$ potential Pareto improvement, even if I pay no money to save the tree. Meanwhile, actual money holds instrumental value, because it can cause potential Pareto improvements. The magnitude of the improvement is equal to the magnitude of the actual money: I am (neglecting transaction costs) willing to pay $\$ 100$ to receive one hundred actual dollars.

There are two substantial objections to defining intrinsic value in terms of potential Pareto improvements. First is that the summing of potential Pareto improvements to form total intrinsic value requires the same cardinality that Paretianism strives to avoid in the first place. This cardinality conflict has been long recognized (see Baumol 1946-1947) but remains often overlooked. Second is that here intrinsic value is being placed on something that does not actually happen, but only could potentially happen. Perhaps advocates of potential Pareto optimality truly do place intrinsic value on this potential-but-not-necessarily-actual phenomenon, but such placement seems strongly counterintuitive.

It may make more sense to describe the potential Pareto improvement as holding instrumental value. In general, the potential to achieve something does seem to be more of an instrumental value than anything else. In this case, the potential Pareto improvement would hold instrumental value because it can cause an actual Pareto improvement, which would then hold component intrinsic value. Placing component intrinsic value on the actual improvement avoids both of the above objections to placing component intrinsic value on the potential improvement. The cardinality objection is avoided because no interpersonal utility comparisons are required if an actual improvement is made. The potentiality objection is avoided because the improvement is actually made. But there is a separate objection. If intrinsic value is defined in terms of actual improvements, then there is no reason to maximize potential improvements without regard to whether compensation is paid. The payment of compensation would be classified as a benefit, in contrast with standard money-based CBA practice. Here the potential compensation principle is 'either redundant or unconvincing' (Sen 2000: 948). Thus treating the potential Pareto improvement as instrumental value also leaves money-based CBA with unsatisfactory justification.

Some have argued that money-based CBA does not need any specific ethical justification. For example, Sunstein (2000: 1061) argues that there can be an 'incompletely theorized agreement' for money-based CBA among people with a broad range of ethical views due to the CBA's ability to help analysts avoid certain cognitive quirks or biases. Similarly, Posner (2000: 1155- 
156) argues that money-based CBA should be used simply because it brings good results: 'I do not want to stake my all on a defense of the Kaldor-Hicks concept of efficiency. For me the ultimate test of cost-benefit analysis employing that concept is a pragmatic one: whether its use improves the performance of government in any sense of improvement that the observer thinks appropriate'. The problem with Posner's argument is that some sort of ethics is needed to evaluate whether the results of the CBA are good. Posner's approach offers little in the many instances in which people disagree about the actions recommended by a CBA. Finally, the ambiguous approaches of Sunstein and Posner are silent on the value types held by money and other forms of costs and benefits, further deterring our ability to evaluate the CBAs and their results. Thus, this ambiguous ethics approach fails to offer adequate ethical foundation for money-based CBA.

There is one formulation of money-based CBA that offers satisfactory justification. Here, the potential Pareto improvement is a signatory value. This view is quite uncommon - indeed, it has only recently been proposed, by Adler and Posner (2006; note that the authors did not discuss the value typology). Adler and Posner define total intrinsic value in terms of a social welfare function with cardinal welfare/utility. They argue that programs that maximize potential Pareto improvements tend to also maximize social welfare. This is similar to the argument of Posner (2000) but with a specific ethical framework in place. Thus potential Pareto improvements signify the occurrence of social welfare increases. Meanwhile, money signifies the occurrence of potential Pareto improvements. They argue that the standard money-based CBA tends to maximize total intrinsic value, defined as social welfare. Furthermore, given the ease of conducting monetary CBAs relative to other analysis techniques, quite often the monetary CBA will lead to the best overall results in terms of this total intrinsic value. Adding nuance, Adler and Posner do not insist that a monetary CBA should always be followed but instead argue that sometimes it should be overruled, such as when the monetary costs fall disproportionately on the poor. Thus Adler and Posner argue that money is a sign but an imperfect one. This is a sophisticated and attractive defense of the standard monetary CBA, one that deserves greater attention. This defense is a plausible response to the argument of Sagoff (2008) that willingness to pay holds no coherent value. The matter could be resolved empirically by clearly defining total intrinsic value and then observing how perfect of a sign willingness to pay is for total intrinsic value. However, Adler and Posner's defense is also quite similar to - and possibly a restatement of - the social welfare-based CBA with a monetary numéraire, which I now turn to.

\section{Value Typology in Social Welfare-Based CBA}

The second form of CBA strives to maximize social welfare. Social welfare is a function of the welfare of all individuals in society. Different social welfare functions represent different ethical views on how social welfare should be aggregated. Meanwhile, individuals' welfare is commonly taken to be a function of their consumption, which is measured in monetary units as in the money-based CBA. The consumption-to-individual-welfare function is known as the utility function. The utility function is not necessarily a linear function of individual consumption. Instead, some consumption (usually that of the poor) is often weighted more than that of others (usually the rich). This weighting is known as distributional weighting (or equity weighting). Social welfare-based CBA has several prominent advocates, including authors of 
some of the foundational treatments of CBA (e.g. Meade 1955; Drèze and Stern 1987; 1990; Drèze 1998). However, it is used less frequently than money-based CBA. The conceptual coherence of social welfare-based CBA is apparent from an analysis of the types of values found in it.

Social welfare-based CBA has some similarities with money-based CBA but also some key differences. Both forms of CBA are anthropocentric in that they both place intrinsic value on human phenomena, though as discussed above money-based CBA is ambiguous on precisely what it places intrinsic value on. Both CBA forms have been developed primarily within economics literatures and thus place much emphasis on monetary consumption. Finally, both forms frequently use a monetary numéraire. However, as discussed below and in contrast with money-based CBA, social welfare-based CBA often uses other numéraires besides money. Furthermore, whereas money-based CBA generally counts all dollars equally (with the exception of future dollars, which are generally discounted), social welfare-based CBA generally weights different dollars differently according to the social welfare function and to handle distributional considerations. There is a fundamental theoretical distinction here: the emphasis on distribution within social welfare-based CBA follows from its use of a cardinal utility function, whereas the emphasis on potential Pareto improvements irrespective of distribution within (many treatments of) money-based CBA follows from its use of an ordinal utility function. Adler and Posner's (2006) advocacy of distributional weighting and cardinal utility is why the monetary-numéraire CBA they defend can be well classified as social welfare-based CBA, even though they don't consider the social welfare-based CBA literature in their work. Either way, the issue of distribution marks a core and contentious divide between advocates of money-based and social welfare-based CBA. Drèze (1998: 488) goes so far as to say that those who do not employ distributional weights 'really do have to get their act together'. Thus while money-based and social welfare-based CBAs have several commonalities, they have distinct theoretical underpinnings and practical implementations. The distinction between the two is further clear in how they set different value types.

In social welfare-based CBA, total intrinsic value is simply the social welfare function. Common social welfare functions include the utilitarian social welfare function, which simply adds up all units of welfare, the Rawlsian maximin social welfare function, which favors the welfare of the worst-off members of society, and the prioritarian social welfare function, which lies between the utilitarian and maximin functions. One could even craft a social welfare function that favors certain patterns of welfare, such as sequences of welfare that increase over time, so as to capture the importance of the narratives of a life (or of a society) discussed by O'Neill (2008), though I suspect that this approach would not fully represent the importance of narratives in that narratives appear to be given a value that goes beyond the mere pattern of welfare. The ability to define the social welfare function in so many different ways depends on the principle of organic unities discussed above. One can agree or disagree with any of these or other particular social welfare functions, as well as on whether to define total intrinsic value in terms of a social welfare function in the first place. However, and in contrast with money-based CBA, there is no confusion regarding what holds total intrinsic value.

There is also no confusion on the value types held by other parts of social welfare-based CBA. Individual welfare holds component intrinsic value. These components are then defined in terms 
of consumption via the utility function. Consumption thus holds instrumental value because it causes welfare. Finally, the numéraire holds signatory value because it signifies the occurrence of whatever values are being expressed with the numéraire. But while it is clear that the numéraire holds signatory value, there can exist some confusion regarding exactly what the numéraire signifies and how perfect of a sign it is.

In principle, social welfare-based CBA allows analysis to be conducted in any numéraire. Money is by far the most common numéraire, though with distributional weighting counting some dollars more than others, in contrast with the unweighted monetary numéraire in money-based CBA. Utility is also often used, for example in CBAs of climate change (Stern, 2007; Nordhaus, 2008). Still other numéraires have received attention. For example, Brekke (1997) uses a numéraire of "environmental units". Each of these numéraires clearly holds signatory value. The confusion with the numéraire comes from the issue of how perfect of a sign any given numéraire is.

Brekke's (1997) paper illustrates the numéraire confusion with a simple example. There are two individuals, each with a different utility function. An action would bring a cost to one individual, a materialist, and a benefit to the other individual, an environmentalist. When the action is evaluated with a monetary numéraire, the action appears to have net benefits. However, when the same action is evaluated with a numéraire of environmental units, then the action appears to have net costs. Thus the action can be accepted or rejected based solely on the choice of numéraire. This result is troubling because the choice of numéraire is supposed to be an insignificant technical detail or matter of convenience. The result further suggests that the regular use of money as the numéraire may lead to analysis consistently biased in the same direction.

Brekke's (1997) result can be addressed by making the numéraire a more perfect sign for social welfare. This greater perfection is achieved by using distributional weights to count some units of money (or other numéraire) more than others. The appropriate distributional weights are those that map increases in the numéraire to proportionate increases in social welfare (Johansson 1998; Drèze 1998). The challenge is in identifying the relationship between monetary units (or any other units) and total intrinsic value. This challenge can be formidable, but it is necessary to properly conduct a social welfare-based CBA.

But even with proper distributional weighting, it may still be the case that not all numéraires are equivalent. A final complication to the use of money in CBA comes from the fact that money carries a certain stigma that other units lack. As a result, monetizing certain costs and benefits, such as the costs and benefits of losing or saving human lives, often provokes harsh reactions. Thus 'the use of money instead of some other unit may therefore send a message that can be conceived as desecrating the value of life' (Hansson 2007: 177; see also Anderson 1993, Chapter 9). Since money is a signatory value in a social welfare-based CBA, other signs with similar behaviors could just as easily be used. For example, instead of measuring willingness to pay in 'dollars', it could be measured in 'points'. Such a neutral numéraire might avoid much of the controversy while still allowing the same analysis. A neutral numéraire would achieve this for both social welfare-based and money-based CBA. 
A further objection to both the money-based and social welfare-based CBAs is their anthropocentrism: both CBAs define total intrinsic value strictly in terms of some form of human welfare. (The unlikely exception is if money holds intrinsic value.) We now turn to intrinsic value-based CBA, which need not be anthropocentric.

\section{Value Typology in Intrinsic Value-Based CBA}

The CBA literature almost always defines CBA in terms of money or social welfare, as discussed above. In this literature, intrinsic value is generally placed on some human phenomenon, often some variant of human preference or welfare. Thus as with the closely-related economic value typology discussed above, the evaluators decide what holds intrinsic value. For example, Fuggitt and Wilcox (1999: 54), in advocating money-based CBA, make it a fundamental principle that CBA 'is anthropocentric, recognizing only humans in the defined society; nonhuman nature does not have standing' (emphasis in original). Fuggitt and Wilcox deserve credit for explicitly stating this anthropocentrism; oftentimes it is only implicitly assumed. However, there are strong grounds for rejecting the anthropocentrism. In this section I consider these grounds and explore a non-anthropocentric, intrinsic value-based CBA.

Three exceptions to the practice of anthropocentrism in CBA I am aware of are Whittington and MacRae (1986), who coin the expression 'the issue of standing' to refer to the question of whose costs and benefits count; Baum (2009a), who explores the question of whether to count costs and benefits to extraterrestrials in the event that humanity encounters an extraterrestrial civilization; and Baum (2009b), who applies the standing concept to the discounting of future costs and benefits. Each of these papers consider granting standing to both sentient non-humans, who may experience costs and benefits in ways similar to humans, as well as non-sentients, who lack the capacity for subjective experience but might merit costs and benefits nonetheless. Including sentient non-humans and non-sentients in this way requires a broader conception of CBA than that found in the money-based or social welfare-based forms.

A similarly broad CBA form can also be found in colloquial discourses. In common parlance, the terms 'cost' and 'benefit' can hold a great variety of meanings. We might speak of the 'human cost' of a disease outbreak or the 'environmental cost' of an oil spill. We might even use these various meanings within cost-benefit reasoning, comparing the pros and cons of one thing or another. Here, one could maintain that CBA is just another term for consequentialist ethics: when an option brings more good consequences (benefits) than bad consequences (costs), then that option should be taken, regardless of any other considerations. Sen (2000) thus notes that CBA can be a form of 'broadly consequential evaluation' in that it parallels consequentialism (p.936) and that 'the language of benefits and costs is used by many who would have nothing to do with cost-benefit analysis as it is standardly practiced' (p.934). To accommodate these broader uses of CBA, a broader concept of CBA is required. Here I develop a broader CBA as intrinsic valuebased $C B A$, in which $C B A$ can be grounded in any choice of intrinsic value, i.e. any choice of phenomenon valuable for its own sake. I also defend the idea that this broader CBA can reasonably be classified as $\mathrm{CBA}$. 
In intrinsic value-based CBA, total intrinsic value can be defined in any way, so long as the resulting ethical framework amounts to some form of consequentialism. What holds component intrinsic value and extrinsic value then follows from whatever holds total intrinsic value. Intrinsic value-based CBA is thus perhaps congruent with consequentialism. (I am not aware of any differences between the two but perhaps they exist nonetheless.) This congruence depends on a very general understanding of the terms cost and benefit, where costs can be any negative consequences and benefits can be any positive consequences. It is due to this parallel between CBA and consequentialism that Sen (2000: 936) refers to CBA as "broadly consequentialist".

Intrinsic value-based CBA can be viewed as an extension of social welfare-based CBA to accommodate intrinsic value other than social welfare. Alternatively, social welfare-based CBA can be viewed as a special case of intrinsic value-based CBA in which intrinsic value is defined exclusively in terms of the welfare of individual humans. Intrinsic value-based CBA can also handle cases in which social welfare is one of multiple phenomena that hold intrinsic value. Here the social welfare function holds component intrinsic value (as does individual welfare).

Intrinsic value-based CBA with social welfare as a component intrinsic value is actually closer to the ethics advocated by the CBA of Adler and Posner (2006) than is social welfare-based CBA, since Adler and Posner make no claim that social welfare functions can accommodate all relevant values. Specifically, they defend weak welfarism, in which 'overall well-being has moral weight, albeit not conclusive weight' (p.39). Adler and Posner cite 'moral rights or intrinsic environmental values' (p.53) as possible other sources of moral weight. As long as whatever other factors hold moral weight are consequentialist, then Adler and Posner's weak welfarism can be defined in terms of intrinsic value-based CBA. However, if they support nonconsequentialist moral factors, then frameworks beyond intrinsic value-based CBA would be necessary. Adler and Posner do not adequately specify what other moral factors they deem relevant, so a final verdict cannot be made.

If the other relevant information is consequentialist, then the advocates' views can be accommodated via intrinsic value-based CBA. That is, the accommodation can be made as long as intrinsic value within the money-based CBA can be clearly specified, a requirement that, as seen above, is often unfulfilled. Furthermore, as with Adler and Posner's weak welfarism, the money-based CBA advocates generally do not specify exactly what other factors are morally relevant. Without such specification, we cannot determine whether the factors can be included within an intrinsic value-based CBA.

While both Adler and Posner's weak welfarism and the money-based CBA can potentially be described in terms of intrinsic value-based CBA, their respective proponents would not do so. (Recall that Adler and Posner's CBA is the same money-based CBA but with a novel justification and also with distributional weighting as in social welfare-based CBA.) Adler and Posner make this point explicitly:

We use the term 'cost-benefit analysis' as applied economists and policy analysts typically do, to mean a monetizing procedure: one that reduces all effects included in the analysis to a dollar amount, and then aggregates. Sometimes, however, 'cost-benefit analysis' is used more generically, to include any wide or multidimensional procedure, not just a monetizing 
one. 'Cost benefit analysis,' in this sense, includes both monetized CBA and intuitive balancing as specific instances. (p.79)

In this passage, the term 'multidimensional procedures' refers to procedures which evaluate values that have different 'dimensions' or qualities. For example, saving money and saving endangered species are qualitatively different, even if CBA would quantify them using the same numéraire metric. Also, 'intuitive balancing' refers to a procedure for intuitively weighing the positive and negative consequences of an action to estimate whether the action should be performed. Under the present paper's nomenclature, intuitive balancing could be a form of intrinsic value-based CBA

It should be noted that Adler and Posner's interpretation of 'cost benefit analysis', though quite commonplace, is actually more narrow than the formal CBA literature, because it omits social welfare-based CBAs that are conducted in non-monetary numéraires. So for example, Brekke's (1997) analysis with a numéraire of environmental units would not qualify as a CBA.

Adler and Posner's interpretation also excludes all other forms of intrinsic value-based CBA, i.e. forms other than the money-based CBA (to the extent that the money-based CBA can be described in terms of intrinsic value-based CBA). Is this exclusion reasonable? Of course the phrase 'cost-benefit analysis' can be defined in any way. But to me it seems unreasonable to adopt this more narrow definition. A simple example demonstrates this.

An example (which I borrow from Baum and Easterling 2010) of CBA that requires a broader definition of 'cost-benefit analysis' is the Intergovernmental Panel on Climate Change (IPCC) definition of adaptation to climate change. The IPCC defines adaptation as 'adjustment in natural or human systems in response to actual or expected climatic stimuli or their effects, which moderates harm or exploits beneficial opportunities' (Watson and the Core Team 2001). This definition is essentially cost-benefit in structure: adaptations strive to avoid costs ('moderate harms') and achieve benefits ('exploit beneficial opportunities'). These costs and benefits can occur to either natural or human systems.

The fact that the IPCC adaptation definition permits costs and benefits to occur to natural systems means that the definition cannot be accommodated by either money-based or social welfare-based CBA. This is because in these two forms of CBA, costs and benefits can only occur to humans (or, perhaps, to money itself in the event that money holds intrinsic value). However, the definition can be accommodated by intrinsic value-based CBA. To make this accommodation, total intrinsic value would be set such that costs and benefits to natural systems hold (negative or positive) component intrinsic value. Since the IPCC definition also includes costs and benefits to human systems, these costs and benefits would also hold component intrinsic value, perhaps via a social welfare function. Adaptation CBAs could be performed which maximized net benefits defined in terms of this hybrid human system/natural system intrinsic value.

In summary, I find it hard to deny that the IPCC adaptation definition must be excluded from the realm of "cost-benefit analysis". Such exclusion would also encompass the numerous other references to non-human costs and benefits found in professional and popular discourses. 


\section{Conclusion}

CBA evaluates possible programs according to the costs and benefits of the consequences of the programs. Costs hold negative value; benefits hold positive value. This paper presents a detailed discussion of the types of values held by costs and benefits, a discussion generally lacking in existing treatments of CBA. For this discussion, I introduce a simple value typology using three value types: intrinsic value (valuable for its own sake), instrumental value (valuable because it causes other value), and signatory value (valuable because it signifies the occurrence of other value). These three value types are shown to play important roles in CBA. Distinguishing between these brings precision and intellectual clarity to our treatments of CBA and helps us avoid important analytical mistakes.

Value typology is discussed for three forms of CBA. First, the standard, money-based CBA measures costs and benefits in monetary units and generally counts all dollars equally. Though by far the most common form of CBA, the money-based CBA is controversial and often conceptually unclear, as seen from the difficulty in identifying what types of value are held by the money-based CBA's components. Second, social welfare-based CBA defines costs and benefits in terms of social welfare and permits analysis in any numéraire. Though less common than money-based CBA, social welfare-based CBA is well-developed in the literature and boasts several prominent supporters. Social welfare-based CBA also features considerably more conceptual clarity than money-based CBA, as seen in the ease of identifying what value types are held by the various components of social welfare-based CBA. Third, intrinsic value-based CBA defines costs and benefits in terms of any choice of intrinsic value. Intrinsic value-based CBA is formally introduced in this paper due to the narrowness of money- and social welfare-based CBA and because the expression 'cost-benefit analysis' is often used more broadly. With intrinsic value-based CBA, CBA can be conducetd for any consequentialist ethical framework.

This paper discusses in detail the types of values held in each of the three forms of CBA. This discussion shows the intellectual clarity of the social welfare- and intrinsic value-based CBAs. In both CBAs, total intrinsic value has a simple, precise definition, and all other values are defined accordingly. The two CBAs are also closely related. Intrinsic value CBA can be viewed as an extension of social welfare-based CBA. Alternatively, social welfare-based CBA can be viewed as a special case of intrinsic value-based CBA. Any specific implementation of social welfare- or intrinsic value-based CBA requires a strong value judgment in the choice of what holds total intrinsic value. One can agree or disagree with such judgments, but at least we know what they are.

The same cannot be said for the money-based CBA, which lacks the clarity of its lesser-known alternatives. This lack of clarity is a major strike against the money-based CBA, one which merits significant attention given this CBA's widespread usage. Indeed, the common practice of counting all dollars equally is unlikely to correspond to whatever ethics we actually hold, especially since few (if any) people place intrinsic value on money itself. To more accurately reflect our ethics, we could retain the monetary numéraire but weight it so that it becomes a more perfect sign of whatever we assign total intrinsic value, be it social welfare or something else. 
Additionally, a more neutral numéraire such as 'points' may be preferable, given the stigma attached to using monetary units to measure certain phenomena such as human life or ecosystem fitness. Either way, this paper's discussion of value typology makes clear that the standard, money-based CBA most likely requires considerable revision.

An important argument against revising money-based CBA is that money-based CBA is easy, an important feature at a time when analysis is expensive. The same argument might be made against paying attention to value typology more generally. While the value typology presented here is conceptually simple, it does add a layer of analytical complexity absent when one ignores the types of values held by costs and benefits. Furthermore, the functional relationships between costs and benefits can make for complex accounting when many diverse costs and benefits are present. The complexity involved in properly implementing and interpreting CBA can make CBA a daunting task. It is thus understandable why so many analysts opt instead for the much easier approach of counting all monetary units equally.

There is a fundamental flaw in this argument against allowing more complexity into CBA, whether through weighting some dollars more than others or through accounting for different value types. The flaw is that such rote simplification forces the analyst to make certain analytical simplifications when others may be more appropriate. Some simplifications are necessary in order to make CBAs of complex phenomena tractable. But which simplifications? In general we will want those simplifications that increase total intrinsic value by lowering the analysis's instrumental cost and increasing its signatory accuracy. Given that the analysis itself can be costly, the optimal approach (relative to whatever ethics are in effect) will involve some simplification, but not necessarily the standard simplifications of weighting dollars equally and ignoring value typology. Indeed, as discussed throughout this paper, these simplifications are often quite inappropriate.

\section{Acknowledgments}

This paper was submitted on 22 August 2009 and accepted on 19 August 2010. Nancy Tuana, Peter Howe, Jouni Paavola, and two anonymous reviewers provided very helpful comments on previous drafts of this paper. The idea that coin collectors might place intrinsic value on money was suggested to me by Nathan Urban. The broader ideas of this paper evolved from several insightful conversations with William Easterling. Any remaining errors or shortcomings are strictly my own.

\section{References}

Ackerman, F. and L. Heinzerling. 2004. Priceless: On Knowing the Price of Everything and the Value of Nothing. New York: The New Press.

Adler, M. D. and E. A. Posner. 2000. 'Introduction'. Journal of Legal Studies 29(2): 837-842.

Adler, M. D. and E. A. Posner. 2006. New Foundations of Cost-Benefit Analysis. Cambridge, MA: Harvard University Press.

Aldred, J. 1994. 'Existence value, welfare and altruism'. Environmental Values 3: 381-402. 
Anderson, E. 1993. Value in Ethics and Economics. Cambridge, MA: Harvard University Press.

Baum, S. D. 2009a. 'Cost-benefit analysis of space exploration: Some ethical considerations'. Space Policy 25(2): 75-80.

Baum, S. D. 2009b. Description, prescription and the choice of discount rates. Ecological Economics 69(1): 197-205.

Baum, S. D. and W. E. Easterling. 2010. 'Space-time discounting in climate change adaptation'. Mitigation and Adaptation Strategies for Global Change 15(6): 591-609.

Baumol, W. J. 1946-1947. 'Community indifference'. Review of Economic Studies 14(1): 44-48.

Beinat, E. and P. Nijkamp (eds.). 1998. Multicriteria Analysis for Land-Use Management. Dordrecht: Kluwer.

Boadway, R. F. and N. Bruce. 1984. Welfare Economics. Oxford: Basil Blackwell.

Bradley, B. 1998. 'Extrinsic value'. Philosophical Studies 91: 109-126.

Brekke, K. A. 1997. 'The numéraire matters in cost-benefit analysis. Journal of Public Economics 64: 117-123.

Broome, J. 1991. 'Utility'. Economics and Philosophy 7: 1-12.

Callicott, J. B. 2002. 'The pragmatic power and promise of theoretical environmental ethics'. Environmental Values 11(1): 3-25.

Cooter, R. and P. Rappoport. 1984. Were the ordinalists wrong about welfare economics?'. Journal of Economic Literature 22(2): 507-530.

Crowards, T. 1997. 'Nonuse values and the environment: Economic and ethical motivations'. Environmental Values 6(2): 143-167.

Drakopoulos, S. 1989. 'The historical perspective of the problem of interpersonal comparisons of utility'. Journal of Economic Studies 16(4): 35-51.

Drèze, J. 1998. 'Distribution matters in cost-benefit analysis: Comment on K.A. Brekke'. Journal of Public Economics 70: 485-488.

Drèze, J. P. and N. H. Stern. 1987. 'The theory of cost-benefit analysis', in A. Auerbach and M. Feldstein (eds.), Handbook of Public Economics (Amsterdam: North-Holland), pp. 909-989.

Drèze, J. P. and N. H. Stern. 1990. 'Policy reform, shadow prices and market prices'. Journal of Public Economics 42: 1-45.

Elster, J. and J. E. Roemer (eds.). 1991. Interpersonal Comparisons of Well-Being. Cambridge, UK: Cambridge University Press.

Fuggitt, D. and S. J. Wilcox. 1999. Cost-Benefit Analysis for Public Sector Decision Makers. Westport, CT: Quorum Books.

Hansson, S. O. 2007. 'Philosophical problems in cost-benefit analysis'. Economics and Philosophy 23: 163-183.

Hayward, T. 1997. 'Anthropocentrism: A misunderstood problem'. Environmental Values 6: 4963.

Hicks, J. 1939. 'The foundations of welfare economics'. Economic Journal 49(196): 696-712.

Holbrook, D. 1997. 'The consequentialistic side of environmental ethics'. Environmental Values 6: 87-96.

Janssen, R. 1992. Multiobjective Decision Support for Environmental Management. Dordrecht: Kluwer.

Johansson, P.-O. 1998. 'Does the choice of numéraire matter in cost-benefit analysis?'. Journal of Public Economics, 70: 489-493.

Kahneman, D. and R. Sugden. 2005. 'Experienced utility as a standard of policy evaluation'. Environmental \& Resource Economics 32: 161-181. 
Kaldor, N. 1939. 'Welfare propositions in economics and interpersonal comparisons of utility'. Economic Journal 49(195): 549-552.

Layard, R. and S. Glaister (eds). 1994. Cost-Benefit Analysis, Second Edition. Cambridge, UK: Cambridge University Press.

Lenman, J. 2000. 'Preferences in their place'. Environmental Values 9(4): 431-451.

McCarthy, D. 2008. 'Utilitarianism and prioritarianism II. Economics and Philosophy 24(1): 133.

McKay, C. P., O. B. Toon and J. F. Kasting. 1991. 'Making Mars habitable'. Nature 352: 489496.

McShane, K. 2008. 'Convergence, noninstrumental value and the semantics of 'love': Comment on Norton'. Environmental Values 17(1): 15-22.

Meade, J. E. 1955. Trade and Welfare. Oxford: Oxford University Press.

Mishan, E. J. 1975. Cost Benefit Analysis: An Informal Introduction. London: Allen \& Unwin.

Mole, R. A. 1995. 'Terraforming Mars with four war-surplus bombs'. Journal of The British interplanetary Society 48: 321-324.

Moore, G. E. 1903. Principia Ethica. Cambridge: Cambridge University Press.

Munda, G. 1995. Multicriteria Evaluation in a Fuzzy Environment: Theory and Applications in Ecological Economics. Heidelberg: Physica-Verlag.

Ng, Y.-K. 2003. 'From preference to happiness: Towards a more complete welfare economics'. Social Choice and Welfare 20: 307-350.

Nordhaus, W. 2008. A Question of Balance: Weighing the Options on Global Warming Policies. New Haven: Yale University Press.

Norton, B. G. 2008. 'Convergence, noninstrumental value and the semantics of 'love': Comment on McShane'. Environmental Values 17(1): 5-14.

O'Neill, J. 2008. 'Happiness and the good life'. Environmental Values 17(2): 125-144.

Pearce, D. 1993. Economic Values and the Natural World. London: Earthscan.

Pearce, D., G. Atkinson and S. Mourato. 2006. Cost-Benefit Analysis and the Environment: Recent Developments. Paris: OECD Publishing.

Porter, T. W. 1995. Trust in Numbers: The Pursuit of Objectivity in Science and Public Life. Princeton: Princeton University Press.

Posner, R. A. 2000. 'Cost-benefit analysis: Definition, justification, and comment on conference papers'. Journal of Legal Studies 29(2): 1153-1177.

Rønnow-Rasmussen, T. and M. J. Zimmerman (eds.). 2005. Recent Work on Intrinsic Value. Dordrecht: Springer.

Sagoff, M. 2008. 'On the economic value of ecosystem services'. Environmental Values 17(2): 239-257.

Sen, A. 2000. 'The discipline of cost-benefit analysis'. Journal of Legal Studies 29(2): 931-952.

Soma, K. 2006. 'Natura economica in environmental valuation'. Environmental Values 15(1): $31-50$.

Spash, C. L. 2007. 'The economics of climate change impacts à la Stern: Novel and nuanced or rhetorically restricted?'. Ecological Economics 63(4): 706-713.

Spash, C. L. 2008. 'How much is that ecosystem in the window? The one with the bio-diverse trail. Environmental Values 17(2): 259-284.

Stern, N. 2007. The economics of climate change: The Stern review. Cambridge, UK: Cambridge University Press. 
Sugden, R. and A. Williams. 1978. The principles of cost-benefit analysis. Oxford: Oxford University Press.

Sunstein, C. R. 2000. 'Cognition and cost-benefit analysis'. Journal of Legal Studies 29(2): 1059-1103.

Watson, R. T. and the Core Team (eds.), 2001. Climate Change 2001: Synthesis Report. A Contribution of Working Groups I, II, III to the Third Assessment Report of the Intergovernmental Panel on Climate Change. Cambridge, UK: Cambridge University Press.

Whittington, D. and D. MacRae, Jr. 1986. 'The issue of standing in cost-benefit analysis'. Journal of Policy Analysis and Management 5(4): 665-682. 